\title{
Characteristics of 'low risk' and 'high risk' dives by young adults: risk reduction in spinal cord injury
}

\author{
JD Blitvich*,1, GK McElroy ${ }^{1}$, BA Blanksby ${ }^{2}$ and GA Douglas ${ }^{2}$ \\ ${ }^{1}$ University of Ballarat, Ballarat, Victoria, Australia; ${ }^{2}$ University of Western Australia, Perth, Western Australia, \\ Australia
}

\begin{abstract}
Study design: To establish benchmark normative data for dive entries performed by young adults of the age range most likely to sustain a diving spinal cord injury. Data acquired from analysis of the dives performed, along with survey information, were used to determine which factors make the most contribution to the level of risk in diving.

Objectives: To identify influential variables which could contribute to risk of spinal cord injury for each of four types of dives. The types of dives investigated were: dive entries from deck level to tread water (Treadwater); deck level to swim $25 \mathrm{~m}$ (Deck); starting block height to swim $25 \mathrm{~m}$ (Block); and a running dive entry to swim $25 \mathrm{~m}$ (Running).
\end{abstract}

Setting: Victoria, Australia.

Methods: Ninety-five first year university students (average age 19.9 years) performed three or four dives which were video-recorded for later analysis. Maximum depth reached was used as an indicator of risk, and velocity at maximum depth, distance at maximum depth, angle of entry and flight distance were measured for each dive. Participants also completed a questionnaire designed to elicit information about their swimming and diving background. Unlike previous diving studies, participants were recreational rather than competitive swimmers. They were not aware that the dive was the focal point, assuming that the researchers were investigating their swimming and treadwater ability.

Results: A stepwise multiple regression was applied to predict depth for each dive condition, and demonstrated that four variables were able to account for $56 \%$ of the variance for Treadwater, $68 \%$ for Deck; $73 \%$ for Running and $79 \%$ for Block. In all conditions involving swimming after the dive (ie Deck, Block and Running), beta weights showed that distance at maximum depth had the greatest influence on the depth of a dive. Flight distance and angle of entry were the next most influential variables. For the Treadwater condition, beta weights showed angle of entry was the most influential variable, followed by velocity at maximum depth, distance at maximum depth and swim rank.

Conclusion: It is recommended that divers strive to surface in as short a distance as possible by maximising flight distance and aiming for a low entry angle. Implementation of steering-up techniques will assist in minimising dive depth.

Sponsorship: This study was supported in part by a grant from the Victorian State Government Department of Human Services, Grampians Region.

Keywords: diving; swimming pool; spinal cord injury

\section{Introduction}

Diving accidents account for $10 \%$ of all admissions to Spinal Injury Units within Australia and approximately $20 \%$ of all cases of quadriplegia. ${ }^{1}$ Walsh $^{2}$ estimated that the financial cost of spinal cord injuries to the Australian community during 1987 was \$127 million. In the 12 month period from June 1996 there were 229 new, persisting cases of spinal cord injury in Australia. ${ }^{3}$ The incidence of new spinal cord injuries incurred

*Correspondence: J Blitvich, School of Human Movement and Sport Sciences, University of Ballarat, PO Box 663, Ballarat, Victoria, Australia 3353 during diving and other water activities was particularly high during this time period, and almost doubled that of the previous 12 months.,

In 1973 Brisbane, Australia, recorded the highest frequency of diving spinal cord injuries in the world. ${ }^{5}$ Those who are injured are rendered tetraplegic and will remain dependent on others for the duration of their life. The grave physical and emotional devastation, and on-going financial costs of aquatic spinal cord injuries must be addressed through prevention programs. ${ }^{6}$ High risk aquatic users need to be distinguished from those at low risk. Behavioural 
and environmental factors must be considered, ${ }^{7}$ as both contribute to the occurrence of aquatic spinal cord injury.

In studies investigating depth attained when swimmers perform dive entries, ${ }^{8-11}$ the type of dive entry has been found to influence depth. In competitive swimming, the scoop start, also known as the pike start or 'dive through the hole' start, requires a higher angle of entry than other competitive starts. Swimmers aim to have the body enter the water through the hole made by the hands. Male swimmers using this start reached an average depth of $1.22 \mathrm{~m}$, compared with $0.74 \mathrm{~m}$ for the flat start and $0.70 \mathrm{~m}$ for the track start. ${ }^{8}$ Female swimmers reached depths of $0.99 \mathrm{~m}$ for the scoop start, and 0.68 and $0.70 \mathrm{~m}$ for the flat and track starts, respectively. Collegiate swimmers reached greater average maximum depths in pike starts than in conventional starts. ${ }^{9}$ When male swimmers dived from $0.75 \mathrm{~m}$ high blocks, they reached an average maximum depth of $0.78 \mathrm{~m}$ using a pike entry and $0.68 \mathrm{~m}$ using a conventional start. For female swimmers, the depths were 0.75 and $0.52 \mathrm{~m}$ for pike and conventional starts, respectively. ${ }^{9}$

Although the scoop entry technique is still used by some competitive swimmers safety concerns have been raised regarding its use. ${ }^{8}$ Welch and Owens ${ }^{9}$ recommend that dive entries from $0.75 \mathrm{~m}$ blocks require a water depth of at least $3.04 \mathrm{~m}$ for recreational swimmers and competitive swimmers learning new dive techniques. For skilled competitive swimmers, they recommend a minimum depth of $1.37 \mathrm{~m}$.

\begin{abstract}
Aims
It was therefore deemed valuable to examine the velocities and depths reached during diving by young adults from the age range most likely to sustain a diving spinal cord injury. Participants completed a survey relating to their swimming and diving history, and performed three or four commonly used dives. The data were analyzed to determine which factors make the most contribution to the level of risk in diving. The maximum depth reached was measured via video recordings to assess the inherent risk.
\end{abstract}

\section{Methodology}

Ninety-five first year students at the University of Ballarat took part in this study (age $19.9 \pm 3.7$ years; height $171.5 \pm 9.0 \mathrm{~cm}$; mass $70 \pm 12.5 \mathrm{~kg}$ ). A questionnaire was completed regarding information about their swimming and diving background, and whether they were self taught to swim and dive, or by an untrained or trained teacher. Approximations of the number of formal swimming lessons they had taken, and their own perception of their swimming and diving skill level were also recorded.

Participants were tested at the University of Ballarat aquatics laboratory. Anatomical landmarks were marked on the left side of the body (the side facing the cameras) at the midline of the ankle, knee, wrist, elbow and shoulder, and at the level of the greater trochanter. A cap with a marker at the external auditory meatus was worn, and the left arm was marked in line with the external auditory meatus when the arms were extended above the head. These markings allowed determination of joint centres during subsequent analysis of dives.

Each participant performed a dive from deck level to tread water after surfacing, and a dive from both deck level and a height of $0.75 \mathrm{~m}$ (the height of standard starting blocks) prior to swimming a length of the $25 \mathrm{~m}$ pool. The dives took place in $2 \mathrm{~m}$ deep water. Thirty-four of the participants also volunteered to complete a running dive entry, with a $2 \mathrm{~m}$ approach, followed by a swim of $25 \mathrm{~m}$. Above and below-water video-recordings were made of each dive using Panasonic S-VHS MS4 and MS5 cameras at a sample rate of $50 \mathrm{~Hz}$. Cameras were positioned $11.5 \mathrm{~m}$ from the divers to ensure the field of view encompassed the whole diving movement. An MS5 camera was used for underwater recordings, where picture quality was paramount. It was positioned $3.5 \mathrm{~m}$ from the end of the pool in a viewing window. Above-water recordings were made using an MS4 camera placed $2.3 \mathrm{~m}$ from the end of the pool (Figure 1). Prior to commencement of the dives, above and below-water reference structures were placed in the plane of movement, and video-recordings were made. The reference structures were of known dimensions, enabling calculation of spatial co-ordinates and analysis of the dives.

Participants were instructed to 'dive in and tread water in front of the camera' and to 'perform a shallow dive and swim to the other end of the pool'. They departed at $30 \mathrm{~s}$ intervals to allow water clarity to be maintained. All participants performed the tread water, deck level and block dives to swim $25 \mathrm{~m}$ in the same sequence. After all standing dives were completed, 34 volunteers each performed a running dive.

After all dives had been recorded, a full explanation of the purpose of the study was made. In the initial explanation, subjects had been told that the investigators were video-recording the dive and the swim (or

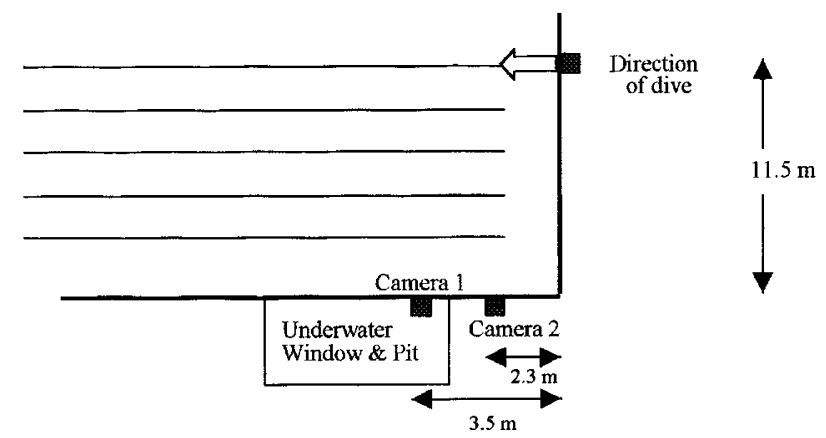

Figure 1 Schematic diagram of equipment set-up 
treadwater), and not that the dive entry alone was of interest. This was an attempt to replicate the circumstances described in the literature, which indicated that people who sustained a diving spinal cord injury did not consider that they were at risk. ${ }^{12,13}$ Questions asked by participants implied that they assumed we were investigating their swimming and treadwater techniques.

The aim of this study was to determine influential variables contributing to the risk of injury for each of four commonly used dives. In each case, the degree of risk (the criterion variable) was operationalised by the measure of the maximum depth reached. Eleven predictor variables considered to be of relevance were measured, viz: distance at maximum depth; velocity at maximum depth; angle of entry; flight distance; height; weight; whether taught to swim and dive by self, or by a qualified or unqualified person; the attended; and a self rating of ability to swim and dive. The first six of these are measured variables and the remaining five are categorical which were coded for the purpose of the data analysis. In view of the anticipated overlap among the predictors, as evidenced in their intercorrelations, stepwise multiple regressions were used for each of the dives. A stepwise multiple regression uses successive contributing predictors as subsequent covariates. This avoids overlapping redundancies and, consequently, selects the most parsimonious set of predictor variables. Comparisons among selected variables were made using the beta weights of the resulting multiple regression equations.

Descriptive statistics have been included to indicate the percentage of participants who allowed their hands to separate during the dive, or pulled their arms back, exposing the unprotected head before or at maximum depth. These data were determined by inspection of the underwater video.

\section{Results}

The means, standard deviations and ranges for the six measured predictors are shown in Table 1. The measurement of maximum depth was taken at the depth of the external auditory meatus, as this landmark could be clearly identified. However, it should be noted that this is an underestimate of the maximum depth reached, as the forehead would be slightly deeper than the external auditory meatus.

Table 2 shows the Labels, Frequencies and Codings for the five categorical variables obtained from the questionnaire. The self ranking of skill level used a Likert scale from 1 (very poor) to 5 (very good).

The results of the stepwise multiple regressions enable the optimal prediction of depth for each dive condition.

Table 1 Means, standard deviations and ranges for four dive conditions (Deck, Block, Running and Treadwater) for six measured predictors.

\begin{tabular}{|c|c|c|c|c|c|}
\hline Variable & & Deck $\mathrm{n}=95$ & Block $\mathrm{n}=95$ & Running $\mathrm{n}=34$ & Treadwater $\mathrm{n}=95$ \\
\hline \multirow[t]{4}{*}{ Maximum depth (m) } & Min & 0.14 & 0.22 & 0.32 & 0.18 \\
\hline & $\operatorname{Max}$ & 1.12 & 1.48 & 1.78 & 1.48 \\
\hline & Mean & 0.49 & 0.64 & 0.67 & 0.66 \\
\hline & SD & 0.19 & 0.27 & 0.28 & 0.24 \\
\hline \multirow{4}{*}{$\begin{array}{l}\text { 1. Maximum distance at } \\
\text { maximum depth }(\mathrm{m})\end{array}$} & Min & 1.75 & 2.62 & 3.00 & 1.64 \\
\hline & Max & 5.75 & 5.96 & 5.78 & 4.5 \\
\hline & Mean & 3.42 & 4.02 & 4.41 & 3.3 \\
\hline & SD & 0.53 & 0.56 & 0.72 & 0.51 \\
\hline \multirow{4}{*}{$\begin{array}{l}\text { 2. Velocity at maximum depth } \\
(\mathrm{m} / \mathrm{s})\end{array}$} & Min & 0.92 & 0.72 & 1.28 & 0.92 \\
\hline & $\operatorname{Max}$ & 3.25 & 3.74 & 3.75 & 3.0 \\
\hline & Mean & 2.31 & 2.55 & 2.75 & 2.06 \\
\hline & SD & 0.50 & 0.64 & 0.58 & 0.45 \\
\hline \multirow[t]{4}{*}{ 3. Angle of entry (degrees) } & Min & 0 & 2 & 4 & 7 \\
\hline & $\operatorname{Max}$ & 50 & 60 & 52 & 62 \\
\hline & Mean & 27 & 34 & 31 & 34 \\
\hline & SD & 9 & 9 & 12 & 9 \\
\hline \multirow[t]{4}{*}{ 4. Flight distance $(\mathrm{m})$} & Min & 1.50 & 2.04 & 2.20 & 1.54 \\
\hline & $\operatorname{Max}$ & 2.92 & 3.56 & 4.18 & 2.86 \\
\hline & Mean & 2.23 & 2.68 & 2.95 & 2.09 \\
\hline & SD & 0.26 & 0.32 & 0.48 & 0.29 \\
\hline \multirow[t]{4}{*}{ 5. Height $(\mathrm{cm})$} & Min & 154.3 & & & \\
\hline & $\operatorname{Max}$ & 193.0 & & & \\
\hline & Mean & 171.7 & & & \\
\hline & SD & 9.0 & & & \\
\hline \multirow[t]{4}{*}{ 6. Weight $(\mathrm{kg})$} & Min & 48.0 & & & \\
\hline & $\operatorname{Max}$ & 115.0 & & & \\
\hline & Mean & 70.0 & & & \\
\hline & SD & 12.5 & & & \\
\hline
\end{tabular}


Table 2 Swim and dive history questionnaire responses

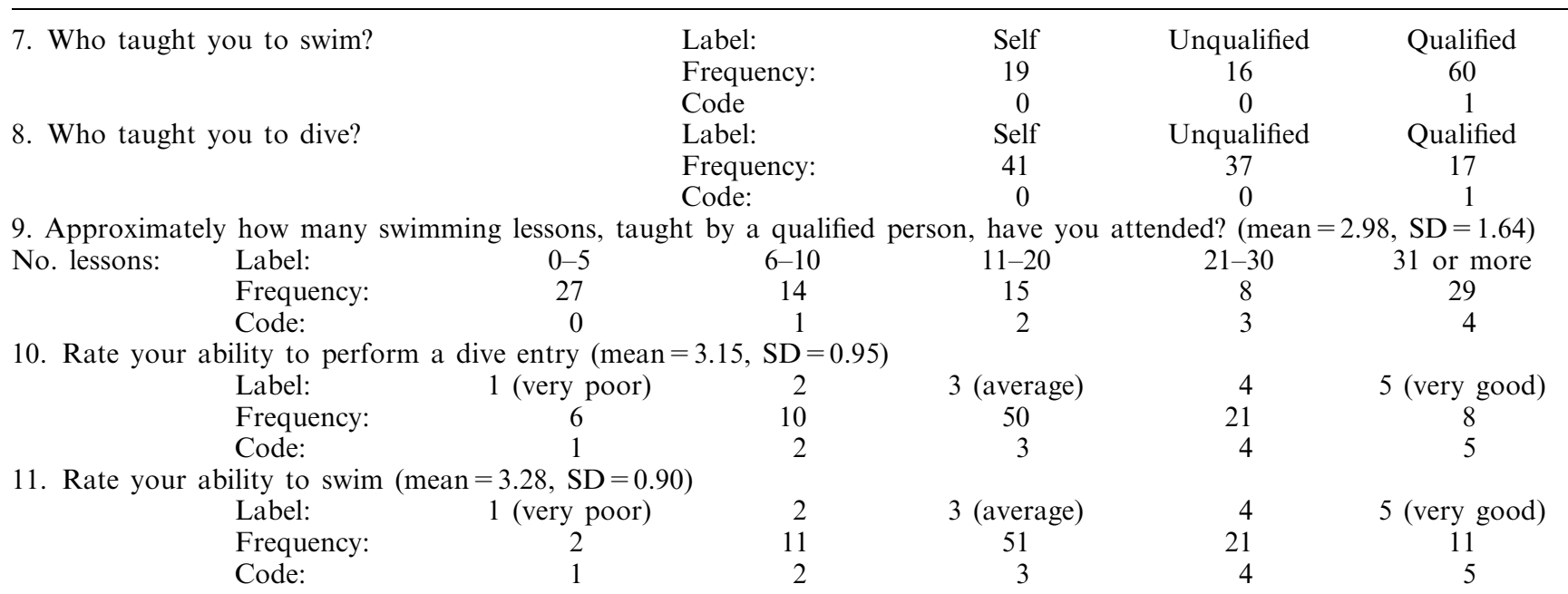

The regression equations for maximum depth in each condition are as follows (see also Table 3 ):

- Deck dive

Predicted depth $=0.27+0.0072$ angle of entry -0.0573 velocity at maximum depth +0.252 distance at maximum depth -0.317 flight distance.

- Block dive

Predicted depth $=0.58+0.387$ distance at maximum depth -0.325 flight distance +0.0097 angle of entry -0.0487 swim rank -0.0046 height.

- Running dive

Predicted depth $=0.24+0.31$ distance at maximum depth -0.303 flight distance +0.0104 angle of entry -0.14 velocity at maximum depth.

- Dive to treadwater

Predicted depth $=0.43-0.226$ velocity at maximum depth +0.0141 angle of entry +0.126 distance at maximum depth -0.0558 swim rank.

Table 3 also includes beta weights. Beta weights indicate the relative importance of each variable. A higher beta weight indicates the importance of the independent variable. The $R$-squared value for each dive condition reveals the percentage of the variance in risk accounted for by the variables in the prediction equation. For the Deck dive, $68 \%$ of the variance in risk is accounted for by the angle of entry; velocity at maximum depth; distance at maximum depth and flight distance. The distance at maximum depth; flight distance; angle of entry; swim ranking and height contributed $80 \%$ of the variance in the Block dive. The Running dive had $73 \%$ of the variance explained by the distance at maximum depth; flight distance; angle of entry and velocity at maximum depth. In the Treadwater condition, $56 \%$ of the variance is accounted for by velocity at maximum depth; angle of entry; distance at maximum depth and swim ranking.
Table 3 Stepwise regression results for prediction of depth for each dive condition

\begin{tabular}{lrrr}
\hline & $\begin{array}{c}\text { Regression } \\
\text { coefficient }\end{array}$ & $\begin{array}{r}\text { Beta } \\
\text { weight }\end{array}$ & $R^{2}$ \\
Variable & & & \\
Condition: Deck & 0.0072 & 0.32 & 0.39 \\
Angle of entry & -0.0573 & -0.15 & 0.55 \\
Velocity of maximum depth & 0.2520 & 0.64 & 0.61 \\
Distance at maximum depth & -0.3170 & -0.42 & 0.68 \\
Flight distance & & & \\
Constant: 0.27 & & & \\
& & & \\
Condition: Block & 0.3870 & 0.83 & 0.42 \\
Distance at maximum depth & -0.3250 & -0.40 & 0.71 \\
Flight distance & 0.0097 & 0.33 & 0.76 \\
Angle of entry & -0.0487 & -0.17 & 0.79 \\
Swim rank & -0.0046 & -0.16 & 0.80 \\
Height & & & \\
Constant: 0.58 & & & \\
& & & \\
Condition: Running & & \\
Distance at maximum depth & 0.3100 & 0.77 & 0.30 \\
Flight distance & -0.3030 & -0.45 & 0.61 \\
Angle of entry & 0.0104 & 0.40 & 0.69 \\
Velocity at maximum depth & -0.1400 & -0.30 & 0.73 \\
Constant: 0.24 & & & \\
Condition: Treadwater & & & \\
Velocity at maximum depth & -0.2260 & -0.41 & 0.27 \\
Angle of entry & 0.0141 & 0.56 & 0.48 \\
Distance at maximum depth & 0.1260 & 0.25 & 0.52 \\
Swim rank & -0.0558 & -0.22 & 0.56 \\
Constant: 0.43 & & & \\
\hline
\end{tabular}

\section{Discussion}

In all dive conditions involving swimming after the dive (Deck, Block and Running entry conditions), the 
beta weights showed that the distance at maximum depth had the greatest influence on the depth of a dive (for Deck, beta weight of 0.64; for Block, 0.83; and for Running, 0.77). This indicates that encouraging a swimmer to surface quickly after a dive entry would assist in decreasing the depth of the dive. In order to surface quickly the swimmer needs to implement techniques to steer the body upwards. This can be achieved by hyperextension of the hands and wrists, raising of the upper trunk to result in a back arch, and slight hyperextension of the neck combined with raising the arms. ${ }^{10}$

An increased flight distance was the next most important variable in minimising the depth of a dive. The beta weights for flight distance were $-0.42,-0.40$ and -0.45 for Deck, Block and Running conditions, respectively. Flight distances can be considered as an indicator of level of confidence in diving. Confident divers 'spring' into the dive, rather than just 'falling forward'. Recommending that swimmers aim to enter the water at least $3.0 \mathrm{~m}$ out from the edge of the pool would help to emphasise the importance of flight distance and decrease the depth of the dive. Flight distances in this study ranged from $1.5-4.18 \mathrm{~m}$, with the greatest flight distances recorded in Running dives. The average flight distance in the Block dive was $2.68 \mathrm{~m}$. This is shorter than flight distances measured in studies investigating competitive swimming starts performed from standard height starting blocks. These range from $2.85 \mathrm{~m}$ for state level age group swimmers ${ }^{14}$ to $3.91 \mathrm{~m}$ reported for college age male swimmers. ${ }^{15}$

On first inspection of the data, it appears counter intuitive that a greater distance at maximum depth and a shorter flight distance both contribute to a deeper dive. To establish how they both contribute to a deeper dive, 40 deep dives with greater distances to maximum depth were analyzed again. Three common factors were observed revealing that a low skill level contributed to increased distances at maximum depth: (1) Most divers who reached the greatest distances at maximum depth made little use of hand, arm and head/neck/back movements as steering techniques. More skilled divers used these movements to surface over a shorter distance; (2) In 15 of the 40 dives, a pulling action with the arms occurred either before or at maximum depth. This resulted in the underwater pathway becoming deeper (ie the divers pulled towards the bottom of the pool) in ten dives, while in the remaining five dives it caused depth to be maintained, rather then expediting the pathway to the surface and (3) The pattern of head movement was different in these 40 dives when compared to the other dives. The usual pattern of head movement in more skilled divers was to hold the head down (chin to chest) upon entry, followed by lifting the head (hyperextending the neck) after entry. This action assisted steering towards the surface. In the deep dives, most divers held their head high (neck hyperextended) or in a neutral position on entry. Consequently, little or no steering effect could be offered by lifting the head after entry.
The variable with the third largest beta weight in each of the dive to swim conditions was angle of entry. Beta weights of $0.32,0.33$ and 0.40 were found for Deck, Block and Running dives, respectively. A greater angle of entry indicates a steeper dive entry and influences the depth achieved in the dive. Angle of entry ranged from $0^{\circ}$ for an inexperienced diver who performed a 'bellyflop'; to $62^{\circ}$, for an experienced competitive swimmer who performed a pike dive during the Treadwater condition. The average angle of entry for the Block dive was $34^{\circ}$, which falls within the average angle of entry range found in studies of competitive swim starts from standard block heights (see Table 4).

Participants with short flight distances are also likely to have steeper entry angles (see Figure 2). Level of confidence and skill both influence angle of entry. Skilled, confident divers who 'spring' forward automatically 'flatten' the angle of entry. In early stages of learning, lack of skill and confidence combine to make the swimmer enter more steeply in most cases as they attempt to avoid the pain of a 'bellyflop'. The steep angle of entry arising from a short flight distance causes the maximum depth to be at a greater distance, even if equal radius of curvature (equal steering skill) is achieved underwater. Given the poorer steering skills likely for the less confident, short flight distance subjects, the distance to maximum depth will be increased further. More confident and skilled divers

Table 4 Angle of entry for dive entries performed from starting block height $(0.75 \mathrm{~m})$

\begin{tabular}{lccc}
\hline Study & Gender & $\begin{array}{c}\text { Type of } \\
\text { dive }\end{array}$ & $\begin{array}{c}\text { Angle of } \\
\text { entry }\end{array}$ \\
\hline Counsilman et $^{\text {al. }}{ }^{8}$ & Male & Scoop & $47^{\circ} \pm 8$ \\
& & Flat & $31^{\circ} \pm 8$ \\
& & Track & $34^{\circ} \pm 8$ \\
& Female & Scoop & $47^{\circ} \pm 7$ \\
& & Flat & $36^{\circ} \pm 8$ \\
Welsh and Owens & & Track & $36^{\circ} \pm 7$ \\
& Male & Pike & $34^{\circ}$ \\
& Female & Conventional & $29^{\circ}$ \\
& & Pike & $31^{\circ}$ \\
Current Study & Mixed & & $34^{\circ} \pm 9$ \\
\hline
\end{tabular}

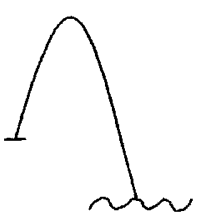

A

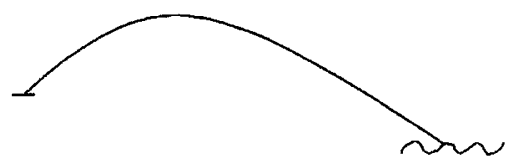

B.
Figure 2 Relationship between flight distance and entry angle. (A) short flight distance, greater angle of entry. (B) long flight distance, smaller angle of entry 
are likely to combine longer flights and shallower entries with superior steering skills to reach maximum depth more quickly.

For the Deck and Running dive conditions, velocity at maximum depth was the final significant variable in the regression analysis. It recorded a beta weight of -0.15 in the Deck dive and -0.30 in the Running dive. For the condition of the Block dive, the diver's self ranking of swimming ability contributed a beta weight of -0.17 while height had a beta weight of -0.16 . These weights are low and add a small but significant contribution to the depth of the dive.

For the Treadwater dive condition, swimmers were instructed to 'dive in and treadwater', rather than the instruction to 'dive in and swim $25 \mathrm{~m}$ ' as for the other three dive conditions. The Treadwater condition was the least predictable of all dive conditions, indicating that variability in technique was greatest in this dive condition. The stepwise multiple regression demonstrated that four variables were able to account for $56 \%$ of the variance for the Treadwater dive as compared to $68 \%$ for the Deck dive, $73 \%$ for the Running dive, and $79 \%$ in the Block condition. However, all of these percentages represent an extensive amount of predictable variation when compared with similar studies using this methodology.

The beta weights for the Treadwater dive did not follow the same pattern as the other three conditions. For Treadwater, the variable with the highest beta weight was the angle of entry (0.56). Velocity at maximum depth, with a beta weight of -0.41 was the next variable, followed by distance at maximum depth $(0.25)$ and swim rank $(-0.22)$. The underwater pathway followed in the Treadwater condition was different from the pathway demonstrated in the dive to swim conditions of the other dives. In the Treadwater condition participants tended to travel 'down and up' more abruptly. In the dive to swim conditions there was more of an 'along' component and in some cases the introduction of propulsive arm or leg movements relatively early in the underwater pathway.

No previous studies investigated a dive to treadwater, although this method of entry is common for recreational water users who are entering the water to 'play' rather than to swim distances. Swimming teachers should place a greater emphasis on the angle of entry for a dive to treadwater, and learners need to be aware of the greater risk of a deck level dive to treadwater when compared to a deck level dive to swim.

The level of risk in any dive entry can be reduced if the diver keeps the hands together and the arms extended beyond the head. ${ }^{10}$ If this position is maintained, the hands and arms offer some protection to the head and neck against impact. Thumbs should be locked, to avoid the arms being forced apart on impact with the water. For 190 dives $(60.1 \%)$ in this study (see Table 5), participants did not lock their thumbs together, which potentially exposes the head without the protection offered by hands and arms. Of even greater concern, during 78 dives $(24.7 \%)$, participants pulled both arms
Table 5 Number of participants with hands together or apart during dive; and number who pulled arms back, exposing head, before or at maximum depth

\begin{tabular}{lccc}
\hline Dive condition & $\begin{array}{c}\text { Hands } \\
\text { separate } \\
(\%)\end{array}$ & $\begin{array}{c}\text { Hands } \\
\text { together } \\
(\%)\end{array}$ & $\begin{array}{c}\text { Pull before/at } \\
\text { maximum } \\
\text { depth }(\%)\end{array}$ \\
\hline Deck & $56(59.6)$ & $38(40.4)$ & $19 / 5(20.2 / 5.3)$ \\
Block & $56(59.6)$ & $38(40.4)$ & $15 / 3(16 / 3.2)$ \\
Running & $24(70.6)$ & $10(29.4)$ & $5 / 3(14.3 / 8.6)$ \\
Treadwater & $54(57.5)$ & $40(42.5)$ & $21 / 7(22.4 / 7.4)$ \\
Total & $190(60.1)$ & $126(39.9)$ & $60 / 18(19 / 5.7)$ \\
\hline
\end{tabular}

backwards before or at maximum depth, thus leaving their head totally unprotected. Swimming teachers should insist that learners lock their thumbs and maintain their arms in an extended position beyond the head until they are close to the surface. In this position, swimmers are maximising head protection throughout the pathway of the dive.

Velocity at maximum depth was determined for 316 dives (three dives were not analyzed as the subjects performed 'bellyflops' and the large number of bubbles produced made it impossible to sight the body markers for measurement). Reports of impact velocities necessary to damage the cervical spine range from $0.61 \mathrm{~m} / \mathrm{s}$ to $3.1 \mathrm{~m} / \mathrm{s} .{ }^{11,12,16,17}$ Stone $^{16}$ stated that an impact velocity of $0.61 \mathrm{~m} / \mathrm{s}$ is sufficient to dislocate the cervical spine, while a velocity of $1.22 \mathrm{~m} / \mathrm{s}$ can crush the cervical spine. In 310 dives ( $98.1 \%$ of dives), the velocity at maximum depth was greater than $1.22 \mathrm{~m} / \mathrm{s}$, indicating the potential to crush cervical vertebrae. ${ }^{16}$ The remaining six dives were all above $0.61 \mathrm{~m} / \mathrm{s}$, the velocity at which cervical vertebrae can be dislocated. ${ }^{16}$

In 14 dives, maximum depth was achieved at a distance of more than $5 \mathrm{~m}$ from the entry edge. The greatest distance was $5.96 \mathrm{~m}$. The velocity in 12 of these dives was in excess of $1.22 \mathrm{~m} / \mathrm{s}$ and for the remaining two dives, more than $0.61 \mathrm{~m} / \mathrm{s}$. As spinal cord injuries can occur from contact with the 'spinal wall', ${ }^{12,18-20}$ it is important to consider these distances and velocities when designing swimming pools.

\section{Conclusions}

The dive entries in this study were typical entries performed by active young adults. The velocities recorded indicate that every dive entry demonstrated potential for a spinal cord injury if impact was made with the bottom or the upslope of the pool. Sustaining a cervical spinal cord injury renders tetraplegic young adults to be financially dependent for the remainder of their lives. Walsh ${ }^{2}$ outlined the initial and ongoing financial cost for a new case of tetraplegia in Australia. It is not possible to place a dollar value on the functional, social and emotional effects of such an injury. 
Blanksby et $a l^{10}$ recommended that introductory diving teaching points should emphasise extension of the arms beyond the head with thumbs locked, combined with implementation of steering-up techniques. The findings of the current study indicate the additional inclusion of the following teaching points:

- As distance at maximum depth was the variable with the greatest influence on dive depth, swimmers should strive to reach the surface in as short a distance as possible after performing a dive. Low skilled divers did not make use of steering methods to direct their underwater pathway upwards. The steering-up techniques outlined by Blanksby et al ${ }^{10}$ should be used, and emphasis should be placed on reaching the surface quickly.

- Once steering skills have been developed, it is safer to encourage swimmers to maximise their flight distances which will also help to achieve shallower, safer dives. As skills and confidence increase, recommending that swimmers enter the water as far out as possible will help them achieve greater flight distances.

- Swimmers should aim for a shallow entry, rather than a steep one. A low entry angle will also help to minimise maximum depth. However, swimmers will prefer a clean, painless entry rather than a stinging 'bellyflop'. Therefore, teachers need to progress carefully through the lead up practices and encourage shallow entry angles.

\section{References}

1 Hill SA, Miller CA, Kosnik EJ, Hunt WE. Pediatric neck injuries. J Neurosurg 1984; 60: 700-706.

2 Walsh J. Costs of spinal cord injury in Australia. Paraplegia 1988; 26: $380-388$.

3 Cripps R, O'Connor P. Spinal Cord Injury, Australia 1996/97. Australian Injury Prevention Bulletin 1998; (18) 1-8.

4 O'Connor P, Cripps R. Spinal Cord Injury, Australia 1995/96. Australian Injury Prevention Bulletin 1997; (16) 1-11.
5 Sutton NG. In: Injuries of the spinal cord: the management of paraplegia and tetraplegia. London: Butterworth, 1973.

6 Blanksby BA, Wearne FK, Elliott BC, Blitvich JD. Aetiology and Occurrence of Diving Injuries: A Review of Diving Safety. Sports Med. 1997; 23: $228-246$.

7 Green LW, Kreuter MW. In: Health Promotion Planning: An Educational and Environmental Approach. 2edn. Mountain View, CA: Mayfield Publishing Company, 1991.

8 Counsilman JE, Counsilman BE, Nomura T, Endo M. Three types of Grab Starts for Competitive Swimming. Swimming Sci. 1979; 1: $81-91$.

9 Welch JH, Owens VL. Water Depth Requirements of Competitive Racing Starts. J Swimming Res. 1986; 2: 5-7.

10 Blanksby BA, Wearne FK, Elliott BC. Safe Depths for Teaching Children to Dive. Australian Science Med. Sport 1996; 3: $79-85$.

11 McElhaney J, Snyder RG, States JD, Gabrielsen MA. Biomechanical Analysis of Swimming Pool Neck Injuries. In: Passenger Protection Committee and Automotive Body Activity, (eds). The Human Neck - Anatomy, Injury Mechanisms and Biomechanics. Warrendale, P.A.: Society of Automotive Engineers, 1979 pp $47-58$.

12 DeMers G. To dive or not to dive: what depth is safe? J. Physical Education, Recreation and Dance 1994; 65: 1 -8.

13 Burke DC. Spinal Cord Injuries from Water Sports. Med. J. Australia 1972; 2: $1190-1194$

14 Pearson CT, McElroy GK, Blitvich JD, Subic A, Blanksby BA. A comparison of the swimming start using traditional and modified starting blocks. J. Human Movement Studies 1998; 34: 49-66.

15 Lewis S. Comparison of five swimming starting techniques. Swimming Technique 1980; 16: $124-128$.

16 Stone RS. In: A rational for rating pools with diving boards. (Arthur D Little Study No. 4). Cambridge, Massachusetts: Arthur D. Little Inc, 1981.

17 Wells R, Bishop P. Cervical spine loading in head first collisions. In: Biomechanics in Sport/Papers prepared for the Engineering in Medicine Group of the Institution of the Mechanical Engineers. Edmunds, Suffolk: Mechanical Engineering Publications Limited; 1988, pp 59-64.

18 American Red Cross. American Red Cross Swimming and Diving. St Louis: Mosby/Yearbook; 1992.

19 Gilbert RR, Langendorfer S. Improving Diving Safety: A Uniform Minimum Safe Diving Depth. National Aquatics Journal 1991; 7: $11-16$.

20 Gabrielsen M, Spivey M. In: The etiology of 486 case studies with recommendations for needed action. Ft. Lauderdale, FL: Nova University Press, 1990. 